\title{
A genome wide analysis of the response to uncapped telomeres in budding yeast reveals a novel role for the NAD+ biosynthetic gene BNA2 in chromosome end protection
} Amanda Greenall ${ }^{* \dagger}$, Guiyuan Lei ${ }^{\dagger \neq}$, Daniel C Swan§, Katherine James ${ }^{\dagger \uparrow}$, Liming Wang ${ }^{\ddagger}$, Heiko Peters ${ }^{\ddagger}$, Anil Wipat ${ }^{\dagger \uparrow}$, Darren J Wilkinson ${ }^{\dagger \neq}$ and David Lydall ${ }^{* * \#}$

\begin{abstract}
Addresses: *Aging Research Laboratories, Institute for Aging and Health, Newcastle University, Newcastle upon Tyne, NE4 5 PL, UK. ${ }^{\dagger}$ Centre for Integrated Systems Biology of Aging and Nutrition, Newcastle University, Newcastle upon Tyne, NE4 5PL, UK. "School of Mathematics \& Statistics, Newcastle University, Newcastle upon Tyne, NE1 7RU, UK. §Bioinformatics Support Unit, Newcastle University, Newcastle upon Tyne, NE2 4HH, UK. "Institute of Human Genetics, International Centre for Life, Newcastle University, Newcastle upon Tyne, NE1 3BZ, UK. ¥School of Computing Science, Newcastle University, Newcastle upon Tyne, NE1 7RU, UK. "Institute for Cell and Molecular Biosciences, Newcastle University, Newcastle upon Tyne, NE2 4HH, UK.
\end{abstract}

Correspondence: David Lydall. Email: d.a.lydall@ncl.ac.uk

Published: I October 2008

Genome Biology 2008, 9:RI46 (doi:I0.1 I86/gb-2008-9-10-r|46)

The electronic version of this article is the complete one and can be found online at http:// genomebiology.com/2008/9/I0/R I46
Received: II August 2008

Revised: 23 September 2008

Accepted: I October 2008

(C) 2008 Greenall et al.; licensee BioMed Central Ltd.

This is an open access article distributed under the terms of the Creative Commons Attribution License (http://creativecommons.org/licenses/by/2.0), which permits unrestricted use, distribution, and reproduction in any medium, provided the original work is properly cited.

\begin{abstract}
Background: Telomeres prevent the ends of eukaryotic chromosomes from being recognized as damaged DNA and protect against cancer and ageing. When telomere structure is perturbed, a coordinated series of events promote arrest of the cell cycle so that cells carrying damaged telomeres do not divide. In order to better understand the eukaryotic response to telomere damage, budding yeast strains harboring a temperature sensitive allele of an essential telomere capping gene (cdc/3I) were subjected to a transcriptomic study.
\end{abstract}

Results: The genome-wide response to uncapped telomeres in yeast $c d c / 3-I$ strains, which have telomere capping defects at temperatures above approximately $27^{\circ} \mathrm{C}$, was determined. Telomere uncapping in $c d c / 3-I$ strains is associated with the differential expression of over 600 transcripts. Transcripts affecting responses to DNA damage and diverse environmental stresses were statistically over-represented. BNA2, required for the biosynthesis of $N A D^{+}$, is highly and significantly up-regulated upon telomere uncapping in $c d c / 3-I$ strains. We find that deletion of $B N A 2$ and $N P T I$, which is also involved in $\mathrm{NAD}^{+}$synthesis, suppresses the temperature sensitivity of $c d c / 3-/$ strains, indicating that $\mathrm{NAD}^{+}$metabolism may be linked to telomere end protection.

Conclusions: Our data support the hypothesis that the response to telomere uncapping is related to, but distinct from, the response to non-telomeric double-strand breaks. The induction of environmental stress responses may be a conserved feature of the eukaryotic response to telomere damage. $B N A 2$, which is involved in $\mathrm{NAD}^{+}$synthesis, plays previously unidentified roles in the cellular response to telomere uncapping. 


\section{Background}

Telomeres are the specialized structures at the ends of linear eukaryotic chromosomes $[1,2]$. Their fundamental configuration is conserved in most eukaryotes and consists of repetitive DNA elements with single-stranded (ss) 3' G-rich overhangs. Telomeres are bound by numerous proteins with specificity for both double-stranded DNA (dsDNA) and the ss overhangs [3] and telomere 'capping' function is critical in preventing the cell from recognizing the chromosome ends as doublestrand breaks (DSBs) [1,3]. Telomeres also need to circumvent the 'end replication problem', which is due to the inability of DNA polymerases to fully replicate chromosome ends [1]. In the presence of telomerase, a reverse transcriptase that uses an RNA template to add telomeric DNA, chromosome ends are maintained by the addition of DNA repeats [4]. In budding yeast and mammalian cells not expressing telomerase, telomeres get progressively shorter with every cell division until they eventually reach a critically short length that is sensed by the DNA-damage apparatus and promotes a cell cycle arrest and replicative senescence [3,5-7]. Cell cycle arrest also occurs when telomere damage is caused by absence or loss of function of telomere capping proteins $[3,8-$ 10].

Telomere degeneration is probably relevant to human cancer and aging [11]. In many human somatic tissues, telomeres become progressively shorter with increasing number of cell divisions. Additionally, age related diseases and premature aging syndromes have been characterized by short telomeres and are associated with altered functioning of both telomerase and telomere-interacting proteins. Regulation of telomere length is also relevant to cancer since, in the majority of human tumors and cancer cell lines thus far examined, telomerase is inappropriately activated, permitting cells to divide indefinitely.

Cdc13 is an essential telomere binding protein in Saccharomyces cerevisiae. Cdc13 is the functional homologue of human Pot1 in that it binds the ss G-tail [12,13]. Cdc13 is involved in telomere length homeostasis, due, at least in part, to its role in the recruitment of the catalytic subunit of telomerase [14-16]. The critical role of Cdc13, however, appears to be in telomere end protection. When $\mathrm{Cdc13}$ is present, telomeres are capped and DNA-damage responses, which would be elicited if telomeres were perceived as DSBs, are suppressed [3]. In the absence of functional Cdc13, uncapping occurs and the resulting dysfunctional telomeres become substrates of the DNA damage response pathway, leading to accumulation of ssDNA at telomeres $[9,17]$, activation of a DNA damage checkpoint $[9,18]$ and eventually cell death $[19,20]$.

CDC13 is an essential gene; however, temperature sensitive alleles such as cdc13-1 allow telomeres to be conditionally uncapped and the resulting cellular response to be studied in detail. This has facilitated identification of the genes required for checkpoint arrest of $c d c 13-1$ strains $[1,3,18,21]$. Telomere uncapping in cdc13-1 strains induces rapid and efficient cell cycle arrest, like many types of DNA damage. Whether uncapped telomeres elicit a different response to that to a DSB elsewhere in the genome remains unknown. A genomewide analysis of the transcriptional response of yeast to deletion of the telomerase RNA subunit revealed that when telomeres become critically short, changes in gene expression overlap with those associated with a number of cellular responses, including the DNA damage response, but also possess unique features that suggest that shortened telomeres invoke a specific cellular response [22]. Telomere damage suffered by yeast cells that lack functional telomerase takes several days to manifest and does so heterogeneously within populations of cells [22]. In contrast, telomere uncapping in cdc13-1 strains exposed to the restrictive temperature is rapid and synchronous, with over $80 \%$ of cells within a population exhibiting the G2-M cell cycle arrest indicative of telomere uncapping within a single cell cycle [18]. We hypothesized that, while the response to telomere uncapping in cdc13-1 strains was likely to overlap with the response to telomerase deletion and DNA damage responses, rapid telomere uncapping in $c d c 13-1$ strains would induce an acute response to telomere damage that would allow us to better dissect, and therefore understand, the response to telomere uncapping.

In this paper, we used DNA microarray analyses to determine the genome-wide response to telomere uncapping in $c d c 13-1$ yeast strains. We show that genes differentially expressed upon telomere uncapping show similarities to expression programs induced by other conditions, such as exogenous cellular stresses and the absence of telomerase. BNA2, encoding an enzyme required for de novo $\mathrm{NAD}^{+}$synthesis, was one of the most highly and significantly up-regulated genes upon telomere uncapping in cdc13-1 strains and has no known function in telomere metabolism. We show that deletion of $B N A 2$ suppresses the temperature sensitivity of $c d c 13^{-1}$ strains; thus, BNA2 plays a role in chromosome end protection.

\section{Results}

\section{Promoting telomere uncapping in cdc/3-I strains}

In order to better understand the eukaryotic response to uncapped telomeres, we examined the genome-wide expression changes associated with telomere uncapping in $c d c 13^{-1}$ yeast strains.

We first sought to determine appropriate conditions to induce telomere uncapping in temperature-sensitive $c d c 13-1$ mutants. The method commonly employed to promote uncapping is to switch from growth at a permissive temperature of $23^{\circ} \mathrm{C}$ to a restrictive temperature of $36^{\circ} \mathrm{C}$ or $37^{\circ} \mathrm{C}$ [23], close to the maximum temperature $\left(38-39^{\circ} \mathrm{C}\right)$ at which wildtype yeast can grow. Transcriptomic profiling of yeast lacking functional telomerase [22] demonstrated that telomere damage affects expression of heat shock genes [22,24]. Since a 
change of culture temperature from $23^{\circ} \mathrm{C}$ to $36-37^{\circ} \mathrm{C}$ would also be sensed as a heat shock, and could potentially cause similar changes in gene expression to those that occur specifically as a result of telomere uncapping, we first tested whether a lower restrictive temperature was able to induce telomere uncapping without a strong heat shock response. We compared restrictive temperatures of $30^{\circ} \mathrm{C}$ (the optimum growth temperature for wild-type yeast) and $36^{\circ} \mathrm{C}$ in $c d c 13^{-1}$ strains.

We first compared the kinetics of cell cycle arrest in cdc13-1 cultures transferred from $23^{\circ} \mathrm{C}$ to $30^{\circ} \mathrm{C}$ or $36^{\circ} \mathrm{C}$ (Figure 1a). cdc13-1 strains transferred to $30^{\circ} \mathrm{C}$ underwent a $\mathrm{G} 2-\mathrm{M}$ cell cycle arrest with broadly similar kinetics to those transferred to $36^{\circ} \mathrm{C}$, with over $80 \%$ of cells in each culture arresting within 2 hours of the temperature shift. Secondly, quantitative RT-PCR was used to examine gene expression in cdc13-1 and $\mathrm{CDC}_{13}{ }^{+}$strains (Figure 1b,c; Additional data file 1). We examined expression of $H S P 12$, which is robustly induced in response to heat stress [24] and also when telomeres are critically short in telomerase deletion mutants [22]. In the $\mathrm{CDC}_{13}{ }^{+}$strain, elevating the culture temperature to $3 \mathrm{O}^{\circ} \mathrm{C}$ caused a mild heat shock, as indicated by 2.3 -fold up-regulation of HSP12 1 hour after altering the temperature (Figure 1b). For the remainder of the time course, HSP12 expression returned to levels slightly below those that were observed before the temperature shift. In the $c d c 13-1$ strain after 1 hour of incubation at $30^{\circ} \mathrm{C}, \mathrm{HSP} 12$ was up-regulated 3.9-fold above levels in the $\mathrm{T}=\mathrm{O}$ sample. By 90 minutes, this induction was reduced to 2.1-fold but then rose steadily at each subsequent time point, presumably due to telomere uncapping, until 4 hours after the temperature shift, when HSP12 was 74-fold up-regulated (Figure 1b).

As expected, switching from growth at $23^{\circ} \mathrm{C}$ to $36^{\circ} \mathrm{C}$ induced a stronger heat shock response than switching to $30^{\circ} \mathrm{C}$. In the $\mathrm{CDC}_{13^{+}}$strain, 1 hour of exposure to $36^{\circ} \mathrm{C}$ induced $H S P 12$ expression 49-fold above levels in the $\mathrm{T}=\mathrm{o}$ sample (Figure 1c). At later time points, $H S P 12$ up-regulation in the $C D C 13^{+}$ strain subsided, although expression was still elevated between 6- and 15-fold above those measured pre-induction. Expression of $H S P 12$ in the $c d c 13-1$ strain transferred to $36^{\circ} \mathrm{C}$ was up-regulated 94-fold after 1 hour and this increased to levels between 132- and 347-fold above the $\mathrm{T}=\mathrm{o}$ sample for the remainder of the time course (Figure 1c).

Additionally, we measured the expression of CTT1 and MSC1 in $c d c 13^{-1}$ and $C D C 13^{+}$strains that had been transferred from $23^{\circ} \mathrm{C}$ to $30^{\circ} \mathrm{C}$ or $36^{\circ} \mathrm{C}$ (Additional data file 1 ). Both of these genes are also up-regulated in response to heat shock [24] and the absence of telomerase [22]. For CTT1, a shift to $36^{\circ} \mathrm{C}$ induced a stronger heat shock response in $\mathrm{CDC}_{13^{+}}$strains than a shift to $30^{\circ} \mathrm{C}$. For $M S C 1$, neither $30^{\circ} \mathrm{C}$ nor $36^{\circ} \mathrm{C}$ appreciably induced gene expression in $\mathrm{CDC}_{13^{+}}$strains. For both of these genes (and also HSP12), differential expression in cdc13-1 strains compared to $C D C 13^{+}$was readily detectible after a shift to $30^{\circ} \mathrm{C}$, indicating that this temperature induces telomere uncapping. Both $30^{\circ} \mathrm{C}$ and $36^{\circ} \mathrm{C}$ can induce heat shock but, as expected, this effect is also more appreciable at $36^{\circ} \mathrm{C}$.

We decided that $30^{\circ} \mathrm{C}$ was a suitable restrictive temperature for examination of the transcriptional response to telomere uncapping as this temperature induces telomere uncapping in $c d c 13-1$ strains whilst causing minimal heat stress.

In order to generate a robust data set, a multi-time-point time course and three biological replicates of each strain were used (Figure 2a). To produce independent biological replicates, we performed a genetic cross between a $C D C 13^{+}$and a $c d c 13-1$ strain to generate three $c d c 13-1$ and three $C D C 13^{+}$strains. The resulting sets of strains demonstrated reproducible cell cycle arrest, growth, viability and HSP12 expression upon exposure to the $30^{\circ} \mathrm{C}$ restrictive temperature (Additional data file 2). Strains were in the S288C genetic background since the $S$. cerevisiae genome sequence was derived from an S288C strain and oligonucleotides on microarray chips are based upon the published genome sequence. Additionally, other large scale genetic screens carried out in our and other laboratories have used this strain background.

\section{Overview of the genomic expression response to telomere uncapping}

cDNAs generated from the three $c d c 13-1$ and three $C D C 13^{+}$ strains treated as in Figure 2a were analyzed using Affymetrix GeneChip ${ }^{\circledR}$ Yeast Genome 2.0 arrays. The entire dataset can be downloaded from the ArrayExpress website, accession number E-MEXP-1551. We used limma [25] to compare transcript levels between $C D C 13^{+}$and $c d c 13-1$ strains at each time point and identified 647 genes with at least two-fold changes in expression levels between $c d c 13-1$ and $C D C 13^{+}$strains and where the differences between $c d c 13-1$ and $C D C 13^{+}$strains showed statistically significant $p$-values $(\leq 0.05$; Figure $2 \mathrm{~b}$; Table A in Additional data file 3). Of these genes, 229 were down-regulated upon telomere uncapping and 418 were upregulated. Analysis of the lists of up- and down-regulated genes using GOstats [26], which identifies statistically overrepresented Gene Ontology (GO) terms, revealed that the upregulated list was enriched for genes involved in processes including carbohydrate metabolism, energy generation and the response to oxidative stress (Table A in Additional data file 4) while the down-regulated list was enriched for genes with roles in processes including amino acid and ribosome biogenesis, RNA metabolism and chromatin modification (Table B in Additional data file 4). Hierarchical clustering was used to investigate the relationships between the differentially expressed genes. This clustering algorithm groups genes with similar expression profiles (Figure 2b). During the time course, the number of differentially expressed genes increased with time (Figure $2 b$ ) and almost all of the changes occurring at early time points persisted for the duration of the experiment (Table 1 and Figure 2b). There were no 


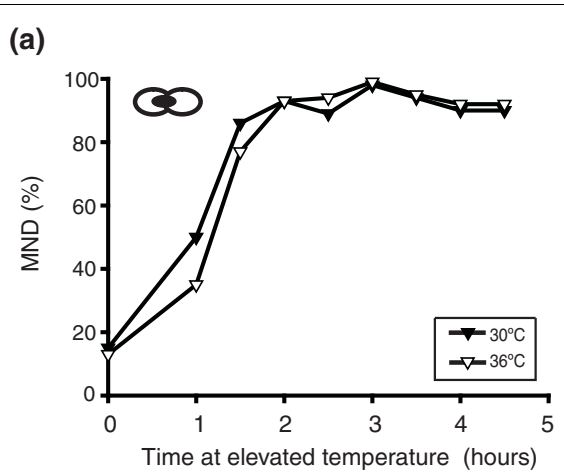

(b)

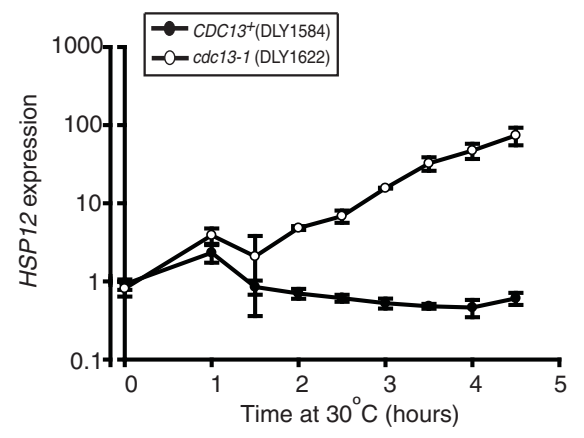

(c)

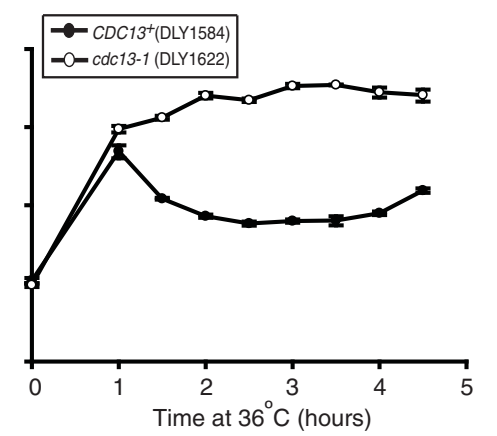

\section{Figure I}

Comparison of $30^{\circ} \mathrm{C}$ and $36^{\circ} \mathrm{C}$ as restrictive temperatures. (a) Two independent cultures of a cdc/3-I strain (DLYI622) grown at $23^{\circ} \mathrm{C}$, were sampled. One culture was transferred to $30^{\circ} \mathrm{C}$ (filled triangles) and the other to $36^{\circ} \mathrm{C}$ (open triangles). Fractions of each culture arrested at medial nuclear division (MND) are shown. (b) $c d c / 3-I$ (DLYI622; open circles) and $\mathrm{CDCI} 3^{+}$(DLYI584; filled circles) strains, grown at $23^{\circ} \mathrm{C}$, were transferred to $30^{\circ} \mathrm{C}$ and samples taken as indicated. RNA was prepared and HSPI2 transcripts were quantified using one-step quantitative RT-PCR. Plotted values represent the means of three independent measurements of each sample and error bars represent the standard deviations of the means. Correction factors to normalize HSPI2 RNA concentrations of each sample were generated by calculating the geometric means of three loading controls, ACTI, PAC2 and BUD6. A single $\mathrm{T}=0$ sample from the $\mathrm{CDCl} 3^{+}$strain was assigned the value of $\mathrm{I}$ and all other values were corrected relative to this. (c) This experiment was carried out as described in (c), except $c d c / 3-I$ and $C D C / 3^{+}$strains were transferred to the restrictive temperature of $36^{\circ} \mathrm{C}$.

differences in gene expression between $c d c 13^{-1}$ and $C D C 13^{+}$ strains before the temperature shift, indicating that in $c d c 13^{-}$ 1 strains, telomeres are functionally capped at $23^{\circ} \mathrm{C}$ (Figure 2b). In $C D C 13^{+}$strains, the expression of 41 genes was altered during the time course. Analysis of this gene list using GOstats [26] demonstrated that genes with roles in cell division and the cell cycle were over-represented in this list (Table $\mathrm{C}$ in Additional data file 4).

In order to validate the microarray data, we used quantitative RT-PCR to examine the expression of five of the up-regulated genes in a set of RNA samples that had been used in the array analysis (Figure 3a). This confirmed that all of the genes examined were up-regulated in $c d c 13^{-1}$ relative to $C D C 13^{+}$. Expression patterns of these same genes in $c d c 13-1$ and $C D C 13^{+}$strains throughout the microarray time course were also examined (Figure 3b). Comparison between gene expression in the microarray experiments with quantitative RT-PCR revealed that while the RT-PCR broadly agreed with the array data, for $U B I 4$ there were differences between gene expres- sion levels quantified using these methods. This may be due to the smaller dynamic range of arrays compared to quantitative RT-PCR. As expected from our pre-array RT-PCR analysis (Figure 1c,d; Additional data file 1), HSP12, CTT1 and $M S C 1$ were up-regulated in our microarray experiment. We plotted the expression of these genes throughout the microarray time course (Additional data file 5) and observed that expression patterns were very similar to those that we had observed by RT-PCR, although like UBI4, expression levels of HSP12 measured in the array were lower than those quantified by RT-PCR.

\section{Expression of genes involved in the response to telomerase deletion}

The transcriptomic response to telomere uncapping in $c d c 13^{-}$ 1 strains was expected to overlap with the response to absence of telomerase [22], since in both cases damaged telomeres activate a checkpoint response. Telomerase deletion is associated with the differential expression of genes involved in processes including the DNA-damage response (DDR) 


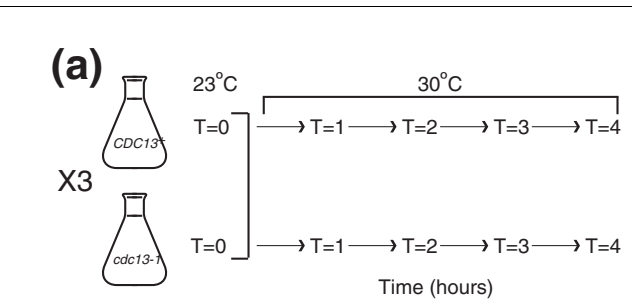

(b)
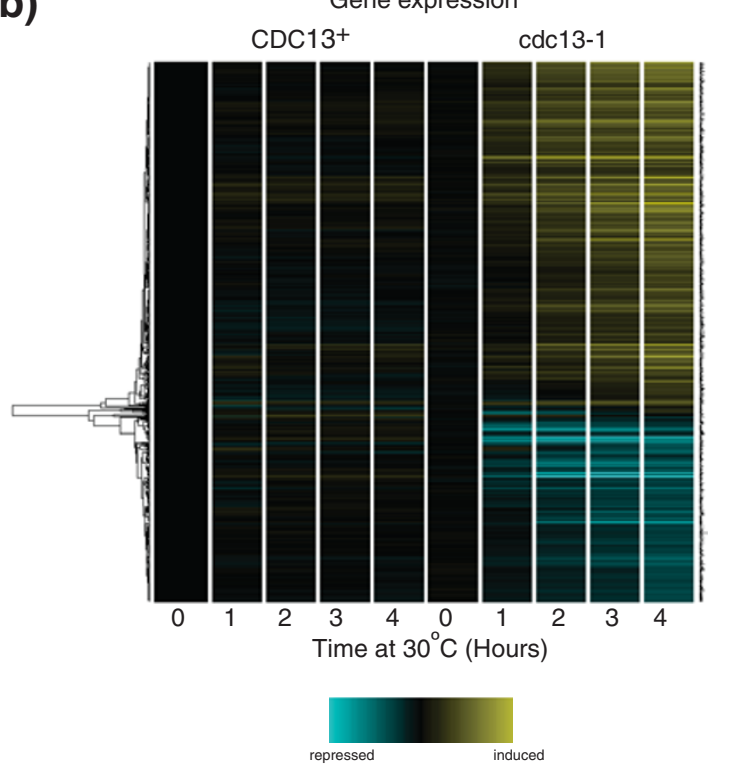

Figure 2

Genome wide expression changes in response to telomere uncapping. (a) Schematic representation of microarray time courses. For each of the three separate time course experiments, one $\mathrm{CDCl}^{+}$and one $\mathrm{cdc} / 3-\mathrm{I}$ strain were inoculated into liquid culture and grown to early log phase at $23^{\circ} \mathrm{C}$. Samples were taken $(T=0)$ and strains were transferred to $30^{\circ} \mathrm{C}$ with further samples taken every 30 minutes from I to 4.5 hours thereafter. Samples from I, 2, 3 and 4 hours after the temperature shift ( $T$ $=I-T=4)$ were used for the array experiment and the remaining samples were stored. (b) Bioconductor was used to hierarchically cluster the 647 differentially expressed genes (DEGs) such that genes whose expression patterns are similar across the time course cluster together. Pearson correlation was used as the similarity measure and average linkage as the clustering algorithm. Expression levels are the averages of the three biological replicates of each sample. Each row represents the expression pattern of a single gene. Each column represents expression levels at a single time point. $\mathrm{CDCl} 3^{+}$strains are on the left and $c d c / 3-1$ strains on the right. Gene names are on the right. Genes shown in yellow are up-regulated, genes shown in blue are down-regulated, while those shown in black are unchanged. All expression values are relative to the $T$ $=0$ time point in $\mathrm{CDCl} 3^{+}$strains. $\log _{2}$ fold-change values are shown. Maximum induction or repression is $2^{(4)}$-fold.

[27,28] and the environmental stress response (ESR) [24]. A significant proportion of the genes differentially expressed in cdc13-1 strains were also involved in similar responses to these (see below for further details), suggesting that different
Table I

\begin{tabular}{lcc} 
Numbers of differentially expressed genes at each timepoint \\
\hline Time at $30^{\circ} \mathrm{C}$ (hours) & Newly DEGs & Total DEGs \\
\hline 0 & 0 & 0 \\
1 & 65 & 65 \\
2 & 181 & 242 \\
3 & 164 & 397 \\
4 & 238 & 616 \\
\hline
\end{tabular}

Total numbers of differentially expressed genes (DEGs) at each time point and those that were not differentially expressed at the previous time point are listed.

types of telomere damage invoke common biological processes.

Direct comparison of the $c d c 13-1$ dataset with the 581 genes altered in the absence of telomerase [22] showed that 244 genes were common to both (Table A in Additional data file $6)$. The overlap may encompass genes whose expression is altered universally in response to telomere damage and includes the DNA damage response genes $R A D 51, R N R 2$, $R N R_{3}$ and $R N R 4$. There were 230 genes up-regulated in cdc13-1 strains but not in the response to telomerase deletion (Table B in Additional data file 6). These include the DNA damage response genes $D U N 1, R A D 16, M A G 1, D D R 2$ and $H U G 1$, and $M S N 4$, which encodes a key transcription factor in the response to environmental stresses [29]. Under conditions of stress, Msn4 and a related protein, Msn2, bind to defined promoter elements called 'stress response elements' (STREs); $36 \%$ of genes up-regulated in cdc13-1 strains possess STREs ( $p \leq 10$ e-15), while only $18 \%$ of genes down-regulated in $c d c 13-1$ strains possess such elements $(p=0.526)$. Therefore, it is probable that up-regulation of $\mathrm{MSN}_{4}$ in the response to telomere uncapping is responsible for the downstream induction of many genes.

Some of the genes differentially expressed in the cdc13-1 experiment but not in response to telomerase deletion may respond specifically to acute telomere damage, while some genes in the tlc1 $\Delta$ data set but not $c d c 13-1$ may be specific to an adaptive response that occurs as cells gradually adapt to telomere erosion over a number of days. We envisaged that because $c d c 13-1$ strains undergo a rapid cell cycle arrest when telomeres are uncapped, use of this system may allow us to identify genes that are involved in the acute response to telomere uncapping. One hour after the temperature shift, the DDR genes DUN1, HUG1, RAD51, RNR2 and $R N_{3} 3$ were already up-regulated in $c d c 13-1$ strains, indicating that damaged telomeres had already been sensed, despite cell cycle arrest not having yet reached maximum levels (Figure 2). $D U N 1$ and $H U G 1$ were not identified as differentially expressed in $t l c 1 \Delta$ strains [22]. 
(a) Q RT-PCR

PNC1

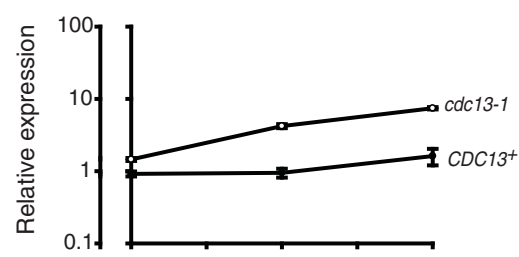

UB/4
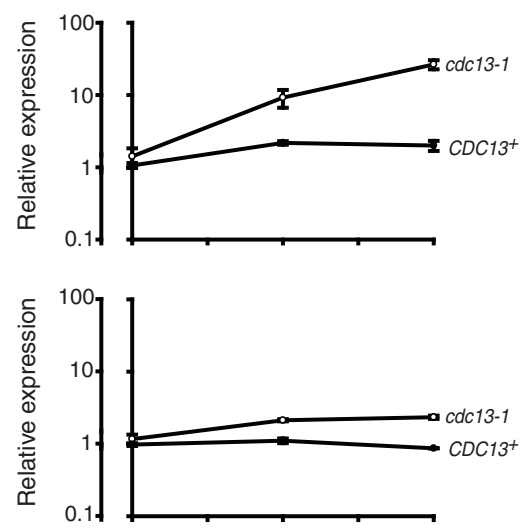

RNR3
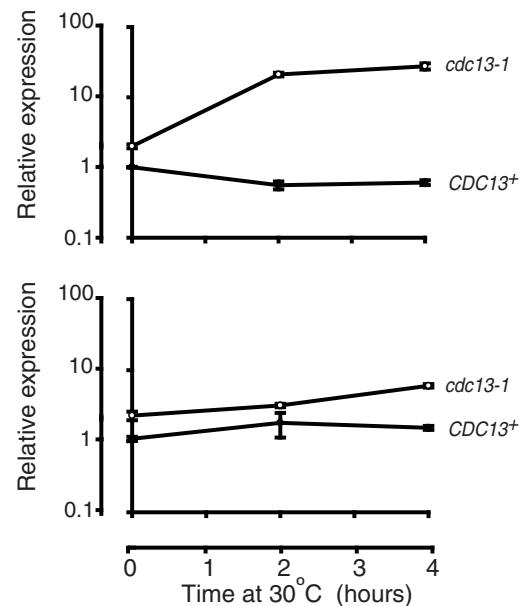

(b) Microarray
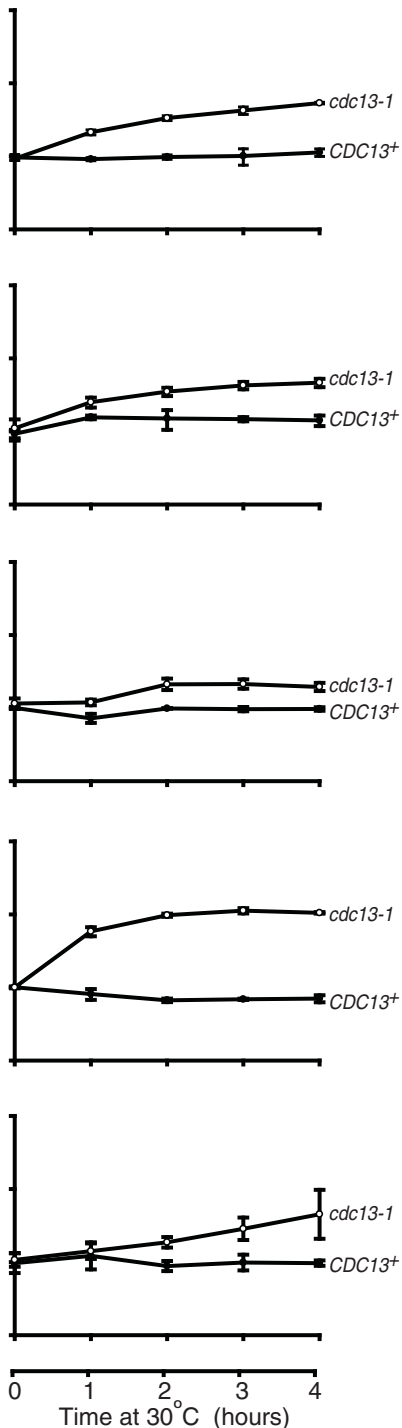

Figure 3

Validation of microarray data. (a) RNA from a single set of time course samples (CDCl3+ (DLY3 I08; filled circles) and cdc/3-I (DLY3I02; open circles)) was subjected to quantitative RT-PCR. Transcript levels of PNCI, UBI4, MAGI, RNR3, and YKLI6IC were analyzed in triplicate. Error bars represent the standard deviations of the means. Correction factors to normalize RNA concentrations were generated by calculating the geometric means of ACTI and PAC2. A single $\mathrm{T}=0$ sample from the $\mathrm{CDCl} 3^{+}$strain was assigned the value of $\mathrm{I}$ and all other values were corrected relative to this. (b) Normalized expression values from the microarray experiment of the five genes of interest quantified and plotted as in (a).

Differences in gene expression between $c d c 13-1$ strains and those lacking telomerase are likely to be due to a number of factors. Firstly, different genes may be altered due to responses to distinct types of telomere damage. Secondly, in a population of cells lacking telomerase, erosion of telomeres and cell cycle arrest occur heterogeneously and over a period of days rather than hours [22], making transcriptional differences less polarized (and thus more difficult to detect) than in a population of rapidly and synchronously arrested $c d c 13-1$ cells. Also, because of heterogeneity of entry into senescence between cultures of telomerase deficient strains [22], results from biological replicates cannot be readily combined to allow statistical analyses such as the ones that we have employed. Additionally, some differences between differentially expressed genes identified in these two experiments are likely because the studies were carried out using different types of arrays and because different algorithms have been used to identify altered gene expression. 


\section{Expression of cell cycle regulated genes}

cdc13-1 strains at the restrictive temperature arrest in the G2$\mathrm{M}$ phase of the cell cycle [18], while $C D C 13^{+}$cells continue to divide. Therefore, the differential expression of many genes in cdc13-1 strains is likely a result of enrichment/depletion of cell cycle-regulated transcripts at the arrest point compared to levels in asynchronous cycling controls. Of the 647 differentially regulated genes in cdc13-1 strains, 256 were shown to be periodically expressed during a recent, comprehensive study of the cell division cycle [30]. A hypergeometric test confirmed that periodically expressed transcripts were overrepresented in our data set ( $p \leq 10 \mathrm{e}-15$; Table 2). Changes in gene expression in $c d c 13-1$ strains displayed a distinct temporal pattern in that total numbers of differentially expressed genes increased at each time point (Figures $2 b$ and $4 a$ ), while cell cycle regulated genes represented an increasingly smaller proportion of the total numbers of differentially expressed genes at each time point (Figure 4a,b). Over 50\% of the genes that are differentially expressed upon telomere uncapping in cdc13-1 strains are not known to be cell cycle regulated; thus, the majority of the observed changes do not seem to be attributable to the G2-M arrest. We subtracted the genes that are known to be cell cycle regulated from our list of 647 differentially expressed genes and subjected the remaining 391 to a GOstats analysis (Table D in Additional data file 4). This list is enriched for genes involved in energy generation and genes involved in nicotinamide metabolism are also over-represented in it $(p=3 \cdot 7 \mathrm{e}-4)$.
It has recently been shown that budding yeast cells disrupted for all S-phase and mitotic cyclins still express nearly 70\% of periodic genes periodically and on schedule, despite being arrested at the G1-S border [30]. Thus, it is possible that despite $c d c 13-1$ strains being arrested at G2-M, this may have a relatively limited effect upon periodic gene expression.

\section{Similarities to DNA-damage and stress responses}

Uncapped telomeres are sensed by cells as if they were DSBs $[9,18]$; thus, the response to telomere uncapping is expected to share features in common with the DDR. Accordingly, many of the genes differentially expressed in $c d c 13-1$ strains have previously been shown to respond to any one of three types of DNA damaging event, namely exposure to ionizing radiation [27], treatment with methyl methanesulfonate [27], or induction of a single, unrepaired cut by $\mathrm{HO}$ endonuclease [28]. A hypergeometric test confirmed that genes differentially expressed in response to any of these types of DNA damaging insult were over-represented in our data set $(p \leq 10$ e15; Table 2). This could be due, at least in part, to the fact that DSBs induce cell cycle arrest at G2-M similarly to uncapped telomeres and, thus, the same sets of transcripts will be enriched/depleted at the arrest point in all cases. In order to account for this effect, we subtracted cell cycle regulated genes [30] from the list of genes differentially expressed in cdc13-1 strains and compared the remaining genes to those that are expressed in response to DNA damage [27,28]. Of the genes altered in $c d c 13-1$ that are not cell cycle regulated, $35 \%$

Table 2

Over-representation of ESR, DDR and CC genes in cdc/3-I dataset and QT clusters

\begin{tabular}{|c|c|c|c|}
\hline Gene set (size) & ESR & DDR & $\mathrm{CC}$ \\
\hline QTI (242) & $33 \%$ & $57 \%$ & $35 \%$ \\
\hline QT2 (160) & $28 \%$ & $51 \%$ & $24 \%$ \\
\hline QT3 (77) & $51 \%$ & $74 \%$ & $49 \%$ \\
\hline QT4 (28) & $57 \%$ & $71 \%$ & $39 \%$ \\
\hline QT5 (23) & $22 \%$ & $61 \%$ & $26 \%$ \\
\hline QT6 (2I) & $0 \%$ & $57 \%$ & $81 \%$ \\
\hline QT7 (9) & $44 \%$ & $78 \%$ & $11 \%$ \\
\hline QT8 (8) & $38 \%$ & $63 \%$ & $25 \%$ \\
\hline QT9 (5) & $0 \%$ & $100 \%$ & $100 \%$ \\
\hline QTIO (8) & $0 \%$ & $25 \%$ & $63 \%$ \\
\hline QTII (6) & $50 \%$ & $67 \%$ & $50 \%$ \\
\hline QTI2 (8) & $0 \%$ & $38 \%$ & $100 \%$ \\
\hline QTI3 (7) & $0 \%$ & $71 \%$ & $100 \%$ \\
\hline Altered in cdc/3-I (647) & $41 \%(P \leq 10 \mathrm{e}-15)$ & $40 \%(P \leq 10 \mathrm{e}-15)$ & $31 \%(P \leq 10 \mathrm{e}-15)$ \\
\hline S. cerevisiae genome & $14 \%$ & $25 \%$ & $22 \%$ \\
\hline
\end{tabular}

Table showing percentage of genes in the S. cerevisiae genome, cdc/3-I dataset and QT clusters I-I 3 that have been shown to be differentially expressed in response to environmental stress, DNA damage, and cell cycle progression. Hypergeometric tests were used to determine whether each class of gene was over-represented in the QT clusters. Percent values shown in bold are statistically over-represented. Gene proportions in the cdc/3-I dataset were compared to expression across the S. cerevisiae genome, while gene proportions in each QT set were compared to proportions across the $c d c / 3-I$ experiment. ESR, all genes involved in the environmental stress response (868) [24]; DDR, all genes that are altered in response to either methyl methanesulfonate, ionizing radiation or a single $\mathrm{HO}$ cut $(I, 529)[27,28]$; CC, all genes known to be cell cycle regulated $(I, 27 \mathrm{I})[30]$ 


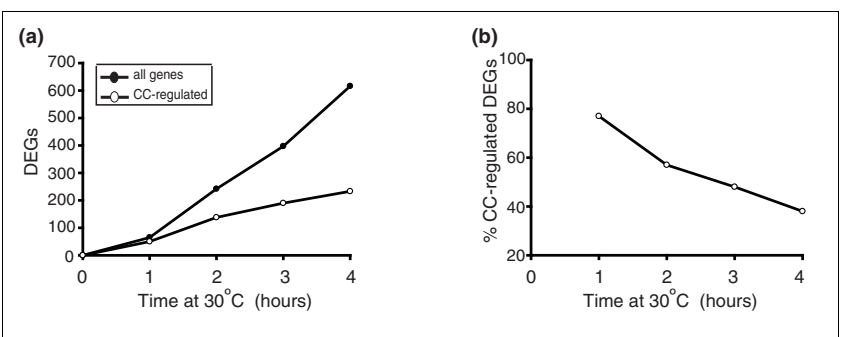

Figure 4

Expression of cell cycle-regulated genes. (a) Total numbers of differentially expressed genes (DEGs) at each time point (filled circles) and numbers of genes at each time point that have been previously classified as cell cycle regulated [30] (open circles) are shown. (b) Percentage of total number of differentially regulated genes at each time point that have been classified as cell cycle regulated [30] are shown.

are also involved in responses to DNA damage, and a hypergeometric test confirmed that the over-representation of DDR genes in this group was statistically significant ( $p \leq 10 \mathrm{e}-$ 15). While genes whose expression is altered in response to telomere uncapping in cdc13-1 strains overlap with those whose expression changes in response to other types of DNA damage, the majority of the altered genes have not been implicated in the DDR, suggesting that uncapped telomeres are not simply sensed as DSBs by cells.

Genome-wide responses to absence of telomerase and to DNA damaging agents share features in common with the ESR. The ESR involves approximately 900 genes whose expression is stereotypically altered in response to diverse environmental conditions [24]. A hypergeometric test confirmed that ESR genes were over-represented in our data set ( $p \leq 10 \mathrm{e}-15$; Table 2). GOstats analysis also demonstrated that significant numbers of genes involved in the response to oxidative stress are present in the list of genes up-regulated in cdc13-1 strains (Table A in Additional data file 4).

\section{Differential expression of transcriptional regulators during telomere uncapping}

In order to identify transcriptional regulators whose expression is altered in $c d c 13-1$ strains, we compared our list of differentially expressed genes to a list of 203 known yeast transcription factors [31]. Fourteen genes encoding transcriptional regulators were up-regulated in cdc13-1 strains (Table A in Additional data file 7). Some of the up-regulated transcription factors are known to play roles in glucose metabolism while MSN4 plays a key role in the ESR (see above). Fourteen genes encoding transcriptional regulators were also down-regulated in cdc13-1 strains (Table B in Additional data file 7). The down-regulated transcription factors appeared to possess diverse roles and worthy of note is the telomeric silencing role of $R A P 1$.

\section{Co-expression of functionally related genes in the response to telomere uncapping}

In order to identify groups of genes that may be co-regulated and/or involved in the same pathways or processes, we subjected genes differentially expressed in $c d c 13-1$ strains to a 'quality threshold' (QT) clustering analysis [32] (Figure 5). This analysis uses an algorithm that groups genes non-hierarchically into high quality clusters based upon similarity in expression patterns. The QT clustering analysis revealed that all but 45 of the genes differentially regulated in cdc13-1 strains can be grouped into 13 QT clusters (Figure 5; Tables B$\mathrm{N}$ in Additional data file 3). In order to identify common properties of genes in each cluster, we used hypergeometric tests to determine whether single clusters had higher than expected numbers of genes that had been implicated in the DDR, the ESR, or were known to be cell cycle regulated (Table 2). Additionally, we carried out a GOstats analysis [26] to determine whether the lists were enriched for genes associated with particular GO terms (Figure 5; Tables E-Q in Additional data file 4). The majority of the QT clusters were enriched for genes with specific GO terms and/or exhibited over-representation of genes involved in the DDR, the ESR or the cell cycle (Table 2). Thus, within some of the sets of coexpressed genes there are significant proportions that clearly share common functions and, as such, their co-ordinate expression may be critical for the cell to mount its response to uncapped telomeres.

\section{Expression of genes linked to telomere function}

Genes with direct roles in telomere function were scarce in the $c d c 13-1$ dataset and, accordingly, GOstats did not identify genes whose products have telomeric roles as being over-represented. Three genes with established roles in telomere maintenance were down-regulated in cdc13-1 strains (HEK2, $R A P 1$ and $T B F 1$ ), while $E S C 8$, which is involved in chromatin silencing at telomeres, was up-regulated. Two separate large scale screens have identified a total of 248 genes that contribute to maintenance of normal telomere length [33,34]. Direct comparison of the $c d c 13-1$ gene expression data set to these showed that five of the up-regulated genes (DUN1, GUP2, $P P E 1, Y B R 284 W$ and $Y S P_{3}$ ) overlapped with these datasets while six of the down-regulated genes (HTL1, LRP1, RPB9, $R R P 8, B R E 1$ and NPL6) have been shown to play a role in telomere length maintenance.

In a separate study, our laboratory has carried out a genomewide screen that has identified more than 240 gene deletions that suppress the temperature sensitivity of $c d c 13-1$ strains and, thus, may play specific roles in telomere capping [35]. With the aim of identifying differentially expressed genes with novel telomeric roles, we compared the list of $c d c 13-1$ suppressors to genes differentially expressed in the $c d c 13-1$ microarrays, and found that 22 genes were common to both (Figure 6a and Table 3). In order to extend the comparison between the two data sets, we used Biogrid [36,37] and Osprey [38] to identify and visualize functional relationships 


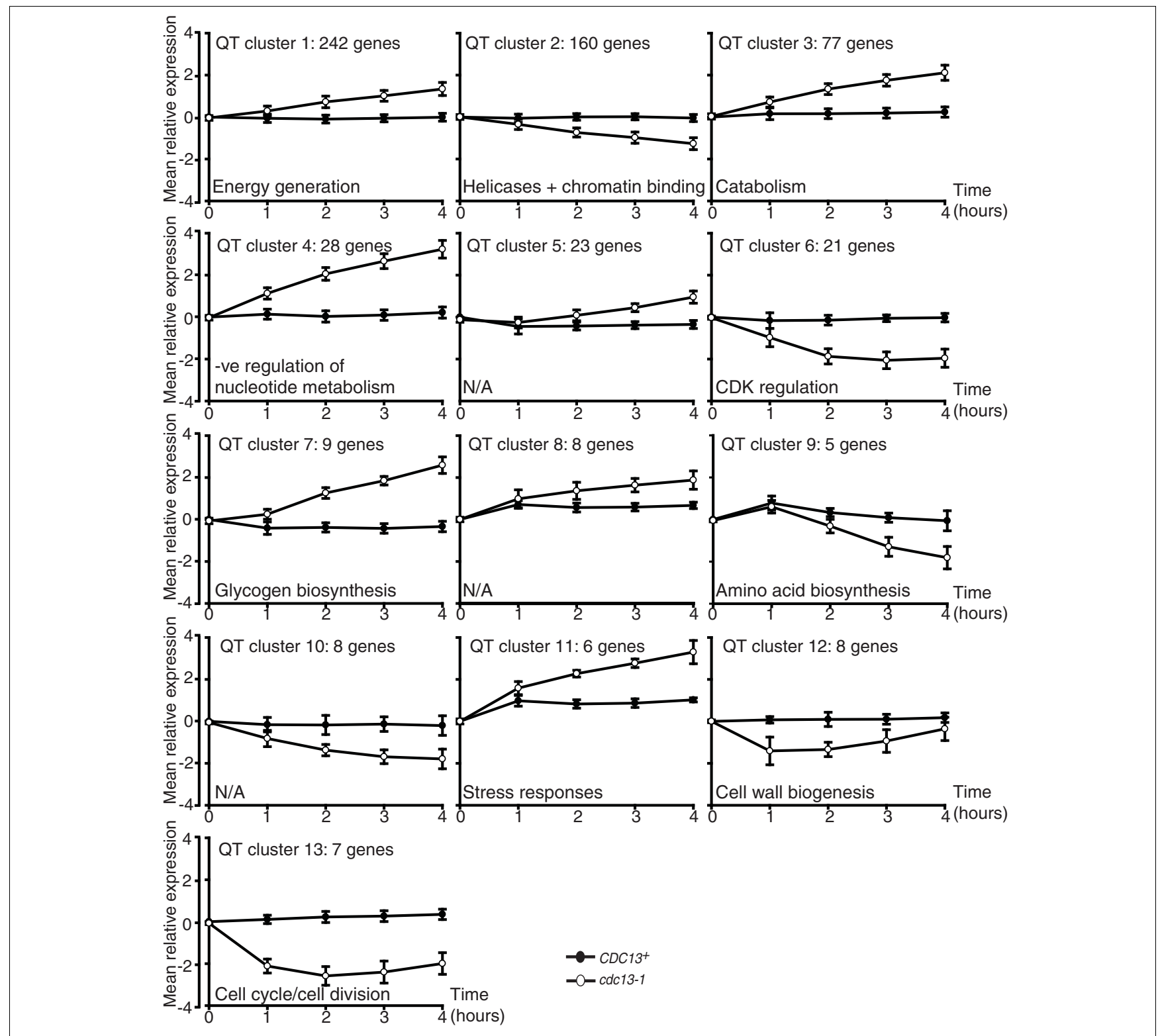

\section{Figure 5}

Quality threshold (QT) clustering analysis of genes differentially expressed upon telomere uncapping. Bioconductor was used to execute a QT clustering analysis [32] of the 647 differentially expressed genes (DEGs). A Euclidean similarity measure was used. Minimum cluster size was 5 and maximum radius of clusters was I.0. Mean expression values of the genes in each cluster relative to the wild-type $T=0$ samples were plotted with error bars representing standard deviations from the mean. Over-represented GO terms for each cluster are indicated.

between differentially expressed genes and those whose deletion suppresses $c d c 13-1$ temperature sensitivity. These functional relationships are based upon protein-protein interactions, co-lethality, co-expression across large numbers of microarray experiments and co-citation in the literature. We were particularly interested in a gene called BNA2, because it was highly and significantly up-regulated in $c d c 13^{-}$ 1 strains (Figure 6b). Differential expression of BNA2 was not observed in the absence of telomerase [22], although it is expressed in response to environmental stress [24]. Biogrid analysis revealed that $B N A 2$ interacts genetically with a cdc13-1 suppressor, NPT1 [35], as co-deletion of these genes is synthetically lethal (Figure 6c). NPT1 is not differentially expressed when telomeres are uncapped in $c d c 3^{-1}$ strains. $B N A 2$ encodes a tryptophan 2,3-dioxygenase required for biosynthesis of nicotinic acid (an $\mathrm{NAD}^{+}$precursor) from tryptophan via the kynurenine pathway [39], while NPT1 encodes a nicotinate phosphoribosyltransferase that acts in the salvage pathway of $\mathrm{NAD}^{+}$biosynthesis and is required for telomeric silencing [40]. 
Table 3

\begin{tabular}{|c|c|c|}
\hline Common name & ID & Function \\
\hline CPA2 & YJRI09C & Large subunit of carbamoyl phosphate synthetase \\
\hline \multirow[t]{3}{*}{ TPSI } & YBRI26C & Synthase subunit of trehalose-6-phosphate synthase/phosphatase complex \\
\hline & YIL055C & Hypothetical protein \\
\hline & YHR087W & Protein involved in RNA metabolism \\
\hline AIRI & YIL079C & RING finger protein \\
\hline$A R X I$ & YDRIOIC & Protein associated with the ribosomal export complex \\
\hline ASHI & YKLI85W & Zinc-finger inhibitor of $\mathrm{HO}$ transcription \\
\hline AYRI & YILI24W & NADPH-dependent I-acyl dihydroxyacetone phosphate reductase \\
\hline CYTI & YOR065W & Cytochrome $\mathrm{cl}$, component of the mitochondrial respiratory chain \\
\hline FYVIO & YIL097W & $\begin{array}{l}\text { Protein of unknown function, required for survival upon exposure to } \mathrm{KI} \text { killer } \\
\text { toxin }\end{array}$ \\
\hline HAP3 & YBL02IC & Subunit of the heme-activated, glucose-repressed Hap2p/3p/4p/5p complex \\
\hline IPKI & YDR3I5C & Inositol I,3,4,5,6-pentakisphosphate 2-kinase \\
\hline LIAI & YJR070C & Protein with a possible role in microtubule function \\
\hline MSN4 & YKL062W & Transcriptional activator related to Msn2p \\
\hline PETI22 & YERI53C & Specific translational activator for the COX3 mRNA \\
\hline QCR2 & YPRI9IW & Subunit 2 of the ubiquinol cytochrome-c reductase complex \\
\hline RNR3 & YIL066C & Ribonucleotide-diphosphate reductase (RNR), large subunit \\
\hline \multirow[t]{2}{*}{$X B P I$} & YILIOIC & Transcriptional repressor that binds to promoter sequences of the cyclin genes \\
\hline & YBRI47W & Hypothetical protein \\
\hline YMC2 & YBRI04W & Putative mitochondrial inner membrane transporter \\
\hline ETRI & YBR026C & 2-enoyl thioester reductase \\
\hline TOSI & YBRI62C & Covalently-bound cell wall protein of unknown function \\
\hline
\end{tabular}

Twenty-two genes whose expression is altered in $c d c / 3-I$ strains and that are also suppressors of $c d c / 3-/$ temperature sensitivity [35].

\section{NAD+ biosynthetic genes and telomere capping}

In order to determine whether $B N A 2$, like $N P T 1$, interacts genetically with $c d c 13-1$, we deleted $B N A 2$ and $N P T_{1}$ in the W303 strain background and compared the abilities of these gene deletions to suppress the temperature sensitivity of cdc13-1 strains. Deletion of BNA2 suppresses the temperature sensitivity of $c d c 13-1$ strains to similar levels as deletion of NPT1, allowing cells to grow at $26^{\circ} \mathrm{C}$ (Figure $7 \mathrm{a}$ ).

$\mathrm{NAD}^{+}$is a ubiquitous biomolecule that is essential for life in all organisms, both as a coenzyme for oxidoreductases and as a source of ADP ribosyl groups [41]. We wondered whether there may be a link between $\mathrm{NAD}^{+}$metabolism and telomere uncapping. NPT1 and BNA2 are both involved in $\mathrm{NAD}^{+}$biosynthesis and deletion of both suppresses the temperature sensitivity of $c d c 13-1$ strains. Additionally, genes associated with the GO term 'nicotinamide metabolic process' are overrepresented in a list of $c d c 13-1$ differentially expressed genes that are not cell cycle regulated (Table D in Additional data file 4). 'Nicotinamide metabolic process' is a GO term that encompasses genes involved in both the synthesis and the consumption of $\mathrm{NAD}^{+}$and its derivatives [42]. The majority of the differentially expressed genes associated with this GO term are up-regulated. Three genes with direct roles in $\mathrm{NAD}^{+}$ biosynthesis are differentially expressed when telomeres are uncapped in $c d c 13-1$ strains. $B N A 2$ and $P N C 1$, which is involved in the NAD salvage pathway [40], are up-regulated, while a down-regulated gene, NMA1 [43], plays roles in both the salvage and the de novo pathways. Because a yeast cell must be able to utilize at least one of these pathways to survive and NMA1 is not an essential gene, NMA1 is clearly not vital for the synthesis of $\mathrm{NAD}^{+}$. This may be because there is a second enzyme called Nma2 with the same biochemical activity as Nma1. Thus, up-regulation of BNA2 and PNC1 could lead to increased $\mathrm{NAD}^{+}$synthesis when telomeres are uncapped. Increased $\mathrm{NAD}^{+}$levels may be required for the response to telomere uncapping because biological processes that increase in cdc13-1 strains include energy production and oxidative phosphorylation (Table A in Additional data file 4), which require $\mathrm{NAD}^{+}$and other up-regulated 'nicotinamide metabolic process' genes that encode products that utilize $\mathrm{NAD}^{+}$or its derivatives, including $N D E 1$ and $N D E 2$, which are involved in NADH oxidation, and YEF1, GND2, and SOL4, which are involved in the synthesis of NADP or NADPH.

$\mathrm{NAD}^{+}$is also required for the activity of Sirtuins, which are deacetylases with conserved roles in DNA repair, heterochromatin formation and lifespan determination [44]. Telomere maintenance appears to be a conserved function of Sirtuins as, in yeast, they are known to play roles in telomeric silencing 


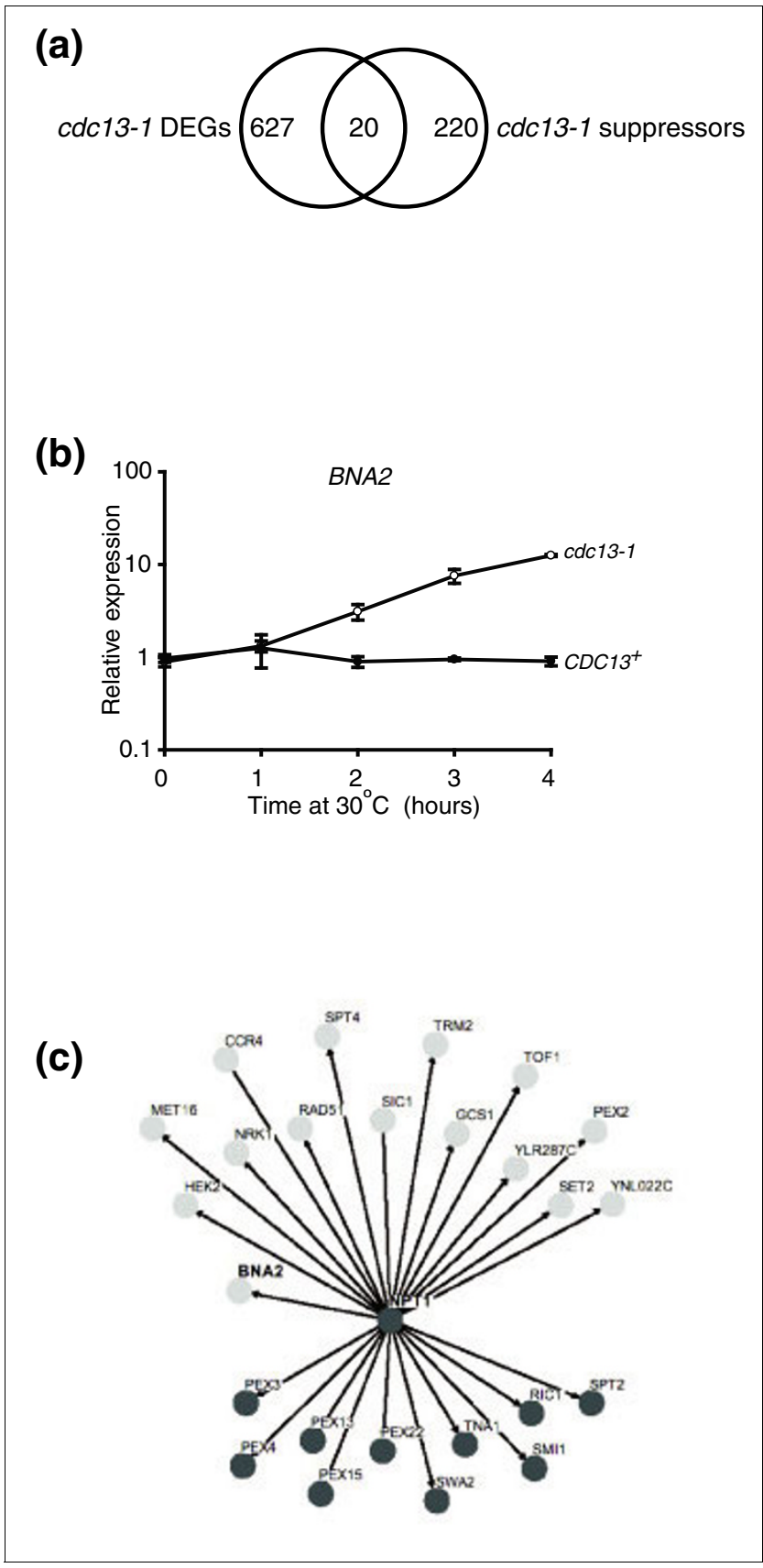

\section{Figure 6}

Differentially expressed genes that suppress the temperature sensitivity of cdc/3-I. (a) Genes that were differentially expressed in $c d c / 3-I$ strains and those that suppress $c d c / 3-I$ temperature sensitivity [35] were plotted using a Venn diagram. (b) Normalized BNA2 expression values from the microarray experiment are plotted as in Figure 3. (c) Functional interactions between BNA2 and genes differentially expressed in cdc/3-I strains or whose deletion suppresses temperature sensitivity of $c d c / 3-I$ were identified and visualized using Biogrid and OSPREY. Nodes shown in light grey represent genes from the $c d c / 3-I$ microarray data set, while nodes shown in dark grey represent genes whose deletion suppresses cdc/3-I temperature sensitivity. Edges represent functional interactions. The edge connecting BNA2 and NPTI represents a 'synthetic lethality' interaction.
[44], and SIRT6, a human Sirtuin, is required for modulation of telomeric chromatin [45].

We wondered whether deletion of BNA2 suppresses $c d c 13-1$ temperature sensitivity via an effect upon Sirtuin function. We hypothesized that bna2s strains may contain reduced $\mathrm{NAD}^{+}$levels when telomeres are uncapped. This may cause decreased Sirtuin activity, leading to reduction of telomeric silencing and increasing accessibility of uncapped chromosomes to the DNA repair machinery. If deletion of BNA2 rescues the temperature sensitivity of $c d c 13-1$ strains via a reduction in Sirtuin function, deletion of Sirtuin genes should also have positive effects upon the growth of $c d c 13-1$ mutants at high temperatures. To test this, we deleted SIR2, and the functionally related SIR4 gene, in $c d c 13-1$ strains. However, in contrast to deletion of BNA2, deletion of SIR2 or SIR4 exacerbates the temperature sensitive phenotype of $c d c 13^{-1}$ strains (Figure 7b). Therefore, we conclude that because deletion of BNA2 has opposite effects upon the temperature sensitivity of $c d c 13-1$ to deletions of SIR2 or SIR4, bna2 $\Delta$ does not suppress $c d c 13^{-1}$ by inhibiting Sirtuin function. To confirm this, we also grew cdc13-1 strains in the presence of nicotinamide, which inhibits Sirtuin function. Consistent with our observation that abrogation of Sirtuin function is deleterious to $c d c 13-1$ strains, nicotinamide inhibited the growth of cdc13-1 strains, while isonicotinamide, which stimulates Sirtuin function, enhanced the growth of $c d c 13-1$ strains (Figure 7c).

To determine whether $B N A 2$ is required to maintain $\mathrm{NAD}^{+}$ levels upon telomere uncapping in cdc13-1 strains, we directly quantified intracellular $\mathrm{NAD}^{+}$. Firstly, we measured $\mathrm{NAD}^{+}$in wild type, npt1 $\Delta$, bna2 $\Delta$ and cdc13-1 strains grown in rich medium at $23^{\circ} \mathrm{C}$ (Figure $7 \mathrm{~d}$ ). Deletion of $B N A 2$ did not reduce $\mathrm{NAD}^{+}$levels under these growth conditions. This was expected because deletion of $B N A 1$, which is in the same linear $\mathrm{NAD}^{+}$biosynthetic pathway as BNA2, has no discernible effects upon intracellular $\mathrm{NAD}^{+}$levels unless nicotinic acid is limiting [40]. In contrast, and as previously observed [46], deletion of $N P T 1$ did lead to a reduction in intracellular $\mathrm{NAD}^{+}$ levels. At $23^{\circ} \mathrm{C}, \mathrm{NAD}^{+}$levels in $c d c 13-1$ strains were comparable to those recorded in wild-type strains. We also measured $\mathrm{NAD}^{+}$levels after telomere uncapping in $c d c 13-1$ strains 2 and 4 hours after a shift to $30^{\circ} \mathrm{C}$, and showed that they did not change notably (Figure $7 \mathrm{~d}$ ). In order to determine whether $B N A 2$ is required to augment $\mathrm{NAD}^{+}$consumed during the response to telomere uncapping, we also examined $\mathrm{NAD}^{+} \mathrm{lev}-$ els in cdc13-1 bna2 $\Delta$ strains before and after telomere uncapping (Figure 7e). Surprisingly, we did not observe any reduction in intracellular $\mathrm{NAD}^{+}$levels upon telomere uncapping in the absence of $B N A 2$. Thus, $B N A 2$ is not required for $\mathrm{NAD}^{+}$homeostasis in response to telomere uncapping but our data do not formally rule out that increased BNA2 expression boosts $\mathrm{NAD}^{+}$. We attempted to over-express $B N A 2$ from a galactose-inducible plasmid to see if this increased intracellular $\mathrm{NAD}^{+}$levels, but found that simply growing cells in galac- 


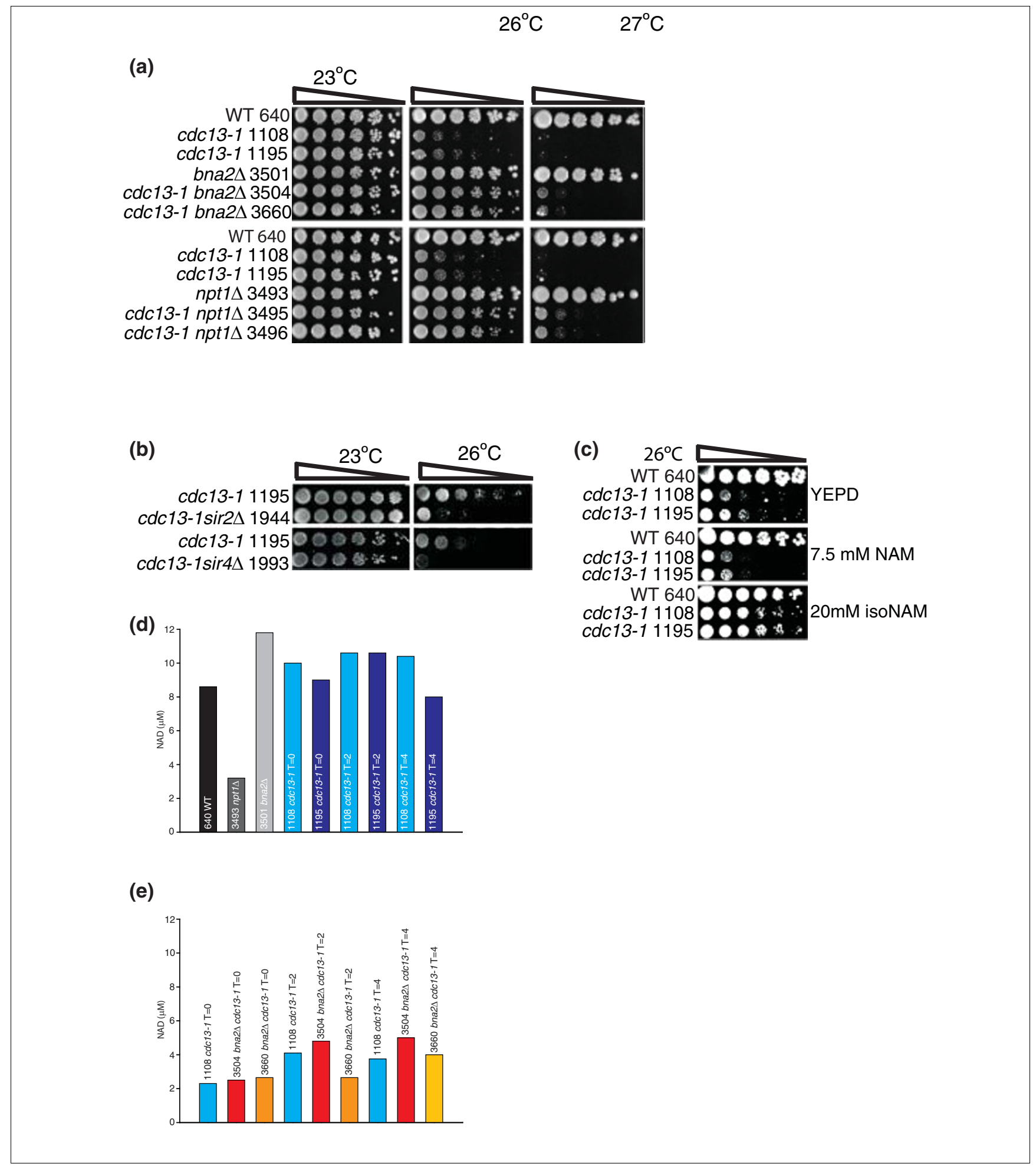

Figure 7

NAD+ biosynthetic genes and Sirtuin function. (a) Six-fold serial dilutions of the indicated strains were spotted onto YEPD plates and grown for 3 days at the indicated temperatures before being photographed. WT, wild type. (b) Six-fold serial dilutions of the indicated strains were spotted onto YEPD plates and grown for 3 days at the indicated temperatures before being photographed. (c) Six-fold serial dilutions of the indicated strains were spotted onto YEPD plates, YEPD plates containing $7.5 \mathrm{mM}$ nicotinamide and YEPD plates containing $20 \mathrm{mM}$ isonicotinamide, and grown for 3 days at the indicated temperatures before being photographed. (d) NAD+ levels in indicated strains; values represent the mean of two measurements. (e) NAD+levels in indicated strains; values represent the mean of two measurements. 
tose led to very high intracellular $\mathrm{NAD}^{+}$levels (data not shown). Telomere uncapping in $c d c 13^{-1}$ strains induces expression of genes involved in de novo $\mathrm{NAD}^{+}$synthesis and also in $\mathrm{NAD}^{+}$salvage. Thus, when telomeres are uncapped in the absence of $B N A 2$, intracellular $\mathrm{NAD}^{+}$levels may be maintained by the $\mathrm{NAD}^{+}$salvage pathway. Further experiments are required to determine the mechanism by which $B N A 2$ affects telomere capping and whether this is related to its role in $\mathrm{NAD}^{+}$biosynthesis.

\section{Discussion}

The genome-wide response to telomere uncapping in cdc/3-I strains

Uncapped telomeres are dangerous to unicellular and multicellular organisms as they are precursors to genomic instability [1]. Hence, conserved cellular responses to damaged telomeres have evolved. Telomere damage in budding yeast leads to a cell cycle arrest $[1,6,22,47]$ that resembles replicative senescence induced by uncapped telomeres in mammalian cells $[7,48]$. Here we show that, in response to acute telomere damage in cdc13-1 yeast strains, cells mount a transcriptional response that exhibits distinct features and that also encompasses aspects of the responses in yeast to the absence of telomerase [22], the DDR [27] and the ESR [24]. Furthermore, the response to uncapped telomeres in $c d c 13-1$ budding yeast strains has features in common with the responses to telomere damage in Schizosaccharomyces pombe [49] and in mammalian cells [50].

\section{Telomere damage induces a response distinct from the DDR}

A major question is whether uncapped telomeres are recognized simply as DSBs or whether the cell senses them as a distinct type of damage. The majority of genes altered in cdc13-1 strains have not thus far been implicated in the DDR, showing that the response to uncapped telomeres is not identical to the response to DSBs at non-telomeric loci. The response to telomerase deletion was also sufficiently different to the DDR for the same conclusion to be drawn [22]. Thus, we confirm that the general cellular response to telomere damage is distinct from the response to DSBs. It is noteworthy that, while telomere uncapping in $c d c 13-1$ strains is associated with the differential expression of many genes involved in the DDR, absent are most of those that are known to be critical for the checkpoint arrest, such as MEC1, DDC2, RAD9, RAD24, $D D C 1, M E C_{3}, R A D 17, R A D 53$ and $C H K 1[1,3]$. Many of these are kinases or kinase regulators and, therefore, may not be expected to be transcriptionally regulated. In fact, differential expression of checkpoint genes was not observed in response to ionizing radiation in $S$. cerevisiae [27] or $S$. pombe [51], suggesting that these genes are primarily regulated at the post-translational level. One exception is the DDR kinaseencoding gene $D U N 1$, which is up-regulated in $c d c 13-1$ strains and in response to other cellular insults [27,51]. Interestingly, DUN1 is also induced in senescent human retinal pigment epithelial cells with shortened telomeres [52], suggesting that its altered expression may be a common feature in response to telomere damage.

\section{Induction of a stress response may be a conserved feature of the response to telomere damage}

A major feature of the response to telomere damage in $c d c 13^{-}$ 1 strains and to the absence of telomerase is the induction of genes involved in the ESR. Telomerase deletion in $S$. pombe is associated with the differential expression of many genes that are also involved in the ESR [49]. A microarray analysis of replicative senescence comparing young human fibroblasts with senescent fibroblasts with shortened telomeres demonstrated that genes involved in stress responses were altered [50], suggesting that telomere damage in mammalian cells is also perceived as a stress. Thus, it appears that the induction of stress responses when telomeres are damaged may be conserved.

\section{NAD+ synthetic genes have roles in telomere capping}

$B N A 2$ is highly and significantly up-regulated when telomeres are uncapped in cdc13-1 strains and is involved in de novo $\mathrm{NAD}^{+}$synthesis [39]. Identification of a functional interaction between $B N A 2$ and a suppressor of $c d c 13-1$ temperature sensitivity, NPT1, suggested that a bna2 $\triangle$ might also suppress it (Figure 6c). This was confirmed as deletion of $B N A 2$ allowed growth of $c d c 13-1$ strains at $26^{\circ} \mathrm{C}$ (Figure $7 \mathrm{a}$ ). That Bna2 inhibits the growth of yeast with telomere capping defects indicates that Bna2 possesses a previously unknown role in the cellular response to telomere uncapping. NPT1 is also involved in the generation of $\mathrm{NAD}^{+}[40]$. Thus, $\mathrm{NAD}^{+}$ metabolism may be linked to responses to telomere uncapping. In support of this hypothesis, GOstats analysis of genes altered in cdc13-1 strains but not periodically expressed during the cell cycle revealed that genes involved in nicotinamide metabolism were over-represented. It is also noteworthy that genes involved in nicotinate and nicotinamide metabolism were over-represented in the list of genes differentially expressed in senescent human fibroblasts with shortened telomeres [50]. Because $\mathrm{NAD}^{+}$is required for the activity of Sirtuins, we investigated whether deletion of BNA2 was exerting its effects upon cdc13-1 via modulation of Sirtuin function. Our experiments suggest that this is not the case (Figure $7 \mathrm{~b}, \mathrm{c})$. It is likely that deletion of NPT1 reduces Sirtuin activity [40,46]. Reduced Sirtuin function has adverse effects upon cdc13-1 (Figure 7b,c), but despite this, npt1 $\Delta$ suppresses the temperature sensitivity of $c d c 13-1$ (Figure 7a) [35]. Thus, cdc13-1 suppression in $n p t 1 \Delta$ strains is likely also independent of any role in modulation of Sirtuin function. $\mathrm{NAD}^{+}$is an abundant biomolecule with many roles within the cell. Further experiments will investigate whether the roles of BNA2 and NPT1 in telomere capping are related to other aspects of $\mathrm{NAD}^{+}$regulation and, if so, how this affects telomere function. 


\section{Conclusions}

Dysregulation of telomere capping is associated with aging and carcinogenesis. To better understand eukaryotic responses to telomere uncapping, we examined the genomewide transcriptional response to telomere uncapping in cdc13-1 yeast strains. The response to uncapped telomeres in cdc13-1 strains has features in common with responses to the absence of telomerase, environmental stress, and to DNA damage at non-telomeric loci. Induction of stress responses appears to be a conserved feature of the eukaryotic response to telomere damage. The BNA2 gene, involved in $\mathrm{NAD}^{+}$synthesis, is highly and significantly induced when telomeres are uncapped in yeast, and its gene product acts to inhibit growth of cdc13-1 mutants. From this, and complementary experiments, we conclude that genes involved in $\mathrm{NAD}^{+}$metabolism play roles in telomere end protection, which has implications for aging and carcinogenesis.

\section{Materials and methods}

\section{Strains, media and growth conditions}

All strains used in the microarray study were in the S288C background (Table 4). All strains used for spot tests were in the W303 genetic background (Table 4). Cultures were grown in YEPD supplemented with $50 \mathrm{mg} / \mathrm{l}$ adenine. Strains for microarray study were grown in medium derived from a sin- gle batch. To construct strains, standard genetic procedures of transformation and tetrad analysis were used [53].

\section{Culture growth, sample collection, RNA isolation and microarray processing}

Cultures were grown overnight at $23^{\circ} \mathrm{C}$ to a density of $3-4 \times$ $10^{6}$ cells $/ \mathrm{ml}$ and diluted as described previously [23]. Cultures were transferred to restrictive temperatures and no further dilutions were made thereafter. Aliquots were taken at each time point to assess cell cycle arrest, viability and cell numbers as described previously [23]. Samples were harvested by spinning at 3,000 rpm for 2 minutes before being snap frozen. RNA was isolated using a hot phenol method followed by purification using Qiagen (Crawley, West Sussex, UK) RNeasy columns [54]. cDNA was prepared, labeled and hybridized to Affymetrix GeneChip Yeast Genome 2.0 arrays, according to the manufacturer's instructions. Arrays were scanned with an Affymetrix Genechip Scanner.

\section{Quantitative RT-PCR}

RNA was prepared as described above and treated with DNAse I from Invitrogen (Paisley, Renfrewshire, UK), according to the manufacturer's instructions. RT-PCRs were carried out using the Invitrogen Superscript III Platinum SYBR green one-step qRT-PCR kit, as prescribed by the manufacturer, using an ABI (Warrington, Cheshire, UK) prism

Table 4

Strains used in this study

\begin{tabular}{|c|c|c|c|}
\hline Name & Genotype & Background & Reference \\
\hline DLY3107 & MAT $\alpha$ mfa::MFAIpr-HIS3 can I ura3 leu2 his3 lys 2 & S288C & This study \\
\hline DLY3108 & MAT $\alpha$ mfa::MFAIpr-HIS3 can I ura3 leu2 his3 lys 2 & S288C & This study \\
\hline DLYI584 & MAT $\alpha$ mfa::MFAIpr-HIS3 can I ura3 leu2 his3 lys2 & S288C & Tong et al. [58] \\
\hline DLY3100 & MAT $\alpha$ cdc/3-I-int mfa::MFA I pr-HIS3 can I ura3 leu2 his3 lys2 & S288C & This study \\
\hline DLY3102 & MAT $\alpha$ cdc/3-int mfa::MFAIpr-HIS3 can I ura3 leu2 his3 lys2 & S288C & This study \\
\hline DLYI622 & MAT $\alpha$ cdc/3-int mfa::MFAIpr-HIS3 can I ura3 leu2 his3 lys2 & S288C & Downey et al[60] \\
\hline DLY640 & MATa ade2-I trpl-I can I-I00 leu2-3, II 2 his3-II,I5 ura3 GAL+ psi+ ssdI-d2 RAD5 & W303 & Zubko et al[6I] \\
\hline DLYII08 & MATa ade2-I trpl-I can I-I00 leu2-3, II2 his3-II,I5 ura3 GAL+ psi+ ssdI-d2 RAD5 cdc/3-I-int & W303 & Zubko et al[6I] \\
\hline DLYII95 & MAT $\alpha$ trp I-I can I-IO0 leu2-3, II2 his3-II,I5 ura3 GAL+ psi+ ssdI-d2 RAD5 cdcl3-I-int LYS+ ade2-I & W303 & Zubko et al[6I] \\
\hline DLYI944 & $\begin{array}{l}\text { MATa cdc/3-I:::int RAD5 sir2::TRPI hml::Ieu2::URA3 ade2-I trp I-I can I-I00 leu2-3, I I } 2 \text { his3-II, I5 ura3-52 } \\
\text { GAL+ psi+ ssdI-d2 }\end{array}$ & W303 & This study \\
\hline DLYI993 & $\begin{array}{l}\text { MATa cdc/3-I::int RAD5 sir4::HIS3 hml::Ieu2::URA3 RAD5 ade2-I trp I-I can I-I00 leu2-3, I I } 2 \text { his3-I I, I } 5 \\
\text { ura3-52 GAL+ psi+ ssd I-d2 }\end{array}$ & W303 & This study \\
\hline DLY350I & MATa bna2::KANMX ade2-I trpl-I can I-I00 leu2-3, I I 2 his3-II, I5 ura3 GAL+ psi+ ssd I-d2 RAD5 & W303 & This study \\
\hline DLY3504 & $\begin{array}{l}\text { MATa bna2::KANMX cdcl3-I-int ade2-I trp I-I can I-I00 leu2-3, I I } 2 \text { his3-II, I5 ura3 GAL+ psi+ ssd I-d2 } \\
\text { RAD5 }\end{array}$ & W303 & This study \\
\hline DLY3660 & $\begin{array}{l}\text { MATa bna2::KANMX cdcl3-I-int ade2-I trp I-I can I-I00 leu2-3, I I his3-I I, I5 ura3 GAL+ psi+ ssd I-d2 } \\
\text { RAD5 }\end{array}$ & W303 & This study \\
\hline DLY3493 & MATa npt I::KANMX ade2-I trpl-I can I-I00 leu2-3,II I his3-II,I5 ura3 GAL+ psi+ ssdI-d2 RAD5 & W303 & This study \\
\hline DLY3495 & $\begin{array}{l}\text { MATa npt I::KANMX cdc/3-I-int ade2-I trpl-I can I-I00 leu2-3, I I } 2 \text { his3-II, I5 ura3 GAL+ psi+ ssd I-d2 } \\
\text { RAD5 }\end{array}$ & W303 & This study \\
\hline DLY3496 & $\begin{array}{l}\text { MAT a npt I::KANMX cdcl3-I-int ade2-I trpl-I can I-I00 leu2-3,II2 his3-II, I5 ura3 GAL+ psi+ ssd I-d2 } \\
\text { RAD5 }\end{array}$ & W303 & This study \\
\hline
\end{tabular}


7700 sequence detector. PCR primers (Table 5) were from Sigma Genosys (Gillingham, Dorset, UK) and were designed using the Invitrogen OligoPerfect designer. In all cases, each measurement was performed in triplicate. Correction factors to normalize RNA concentrations of each sample were generated by quantification of up to three loading controls (ACT1, PAC2 and BUD6). Where indicated, the geometric means of multiple loading controls were calculated [55].

\section{Analysis of microarray data}

CEL files and MIAME-compliant information for those files were stored internally in the CISBAN SyMBA repository [56]. SyMBA is an open-source project that provides an archive and web interface for multi-omics experimental data and associated metadata. Raw data is publicly available from the ArrayExpress website, accession number E-MEXP-1551. To identify significant differentially expressed genes whose expression was altered in $c d c 13-1$ strains relative to $C D C 13^{+}$at least two-fold during at least one time point in all three replicates, CEL files were loaded into Bioconductor [57] and the data normalized using RMA. The list of significantly differentially expressed genes used for subsequent analysis was based on the limma contrasts 'm1-w1', 'm2-w2', 'm3-w3', 'm4w4'. The probe sets with F-test $p$-value (adjusted using the 'Bonferroni' method for multiple testing) lower than 0.05 are identified as significantly differentially expressed. GOstats

Table 5

\begin{tabular}{|c|c|c|}
\hline Primer & Alias & Sequence \\
\hline 1082 & ACTIF & GCCTTCTACGTTTCCATCCA \\
\hline 1083 & $A C T I R$ & GGCCAAATCGATTCTCAAAA \\
\hline 1367 & $P A C 2 F$ & AATAACGAATTGAGCTATGACACCAA \\
\hline 1368 & $P A C 2 R$ & AGCTTACTCATATCGATTTCATACGACTT \\
\hline 1172 & BUD6F & CAGACCGAACTCGGTGATTT \\
\hline 1173 & BUD6R & TTTTAGCGGGCTGAGACCTA \\
\hline 1163 & HSPI $2 \mathrm{~F}$ & AAGGTCGCTGGTAAGGTTCA \\
\hline 1164 & $H S P I 2 R$ & GCTTGGTCTGCCAAAGATTC \\
\hline 1244 & PNCIF & T T G T G G TCACCAGAGATTGG \\
\hline 1245 & PNCIR & CT G G C CTTGGAGAGTGGTAG \\
\hline 1242 & UBI4F & G G TATTCCTCCAGACCAGCA \\
\hline 1243 & UBI4R & $T A C \subset A C \subset C C T \subset A A \subset C T \subset A A G$ \\
\hline 1234 & MAGIF & $T \subset A A \subset A G A T \subset A G T G G \subset \subset A A G$ \\
\hline 1235 & MAGIR & GCACATTTTGCTGGGTCTTT \\
\hline 1246 & RNR3F & CAGGGTTTGGCCGATACTTA \\
\hline 1247 & RNR3R & СTTCTTTTTGGGCCAATTCA \\
\hline 1248 & $Y K L I 6 / C F$ & T G G C C GAACTACT T G G TAG G \\
\hline 1249 & $Y K L / 6 / C R$ & G CAATGTTTCCTCAGGTGGT \\
\hline 1165 & MSCIF & TCTTCGGATCACCCAGTTTC \\
\hline 1166 & $M S C I R$ & G AAGCCTTAGCGTCGTCAAC \\
\hline 1084 & CTTIF & AAAGAGTTCCGGAGCGTGTA \\
\hline 1085 & CTTIR & ACGGTGGAAAAACGAACAAG \\
\hline
\end{tabular}

analyses [26] were carried out using GOstats version 2.6.0 and data were subjected to conditional hypergeometric tests with a cut-off of 0.01 .

\section{Creation of W303 deletion strains}

Deletion constructs were amplified by PCR from S288C gene deletion library strains, in which genes have been replaced with a KANMX cassette [58]. Primers are described in Table 6. PCR fragments were transformed into the diploid $\mathrm{W}_{303}$ strain DDY145 (cdc13-1/CDC13 ${ }^{+}$rad9::HIS3/RAD9 ${ }^{+}$) as described previously [59], with an additional incubation for 2 hours at $23^{\circ} \mathrm{C}$ at the end of the protocol. Transformants were selected based upon $\mathrm{G} 418$ resistance and gene deletions were confirmed by PCR, using forward ( 5 ') primers (Table 6) and reverse primer 1261 (TCAGCATCCATGTTGGAATT), which anneals to the G418 cassette. Diploids were sporulated, tetrads dissected and progeny selected.

\section{Spot tests}

Cultures ( $2 \mathrm{ml}$ ) were grown overnight to saturation, diluted to $\mathrm{OD}_{600}=1$ and then subjected to a six-fold dilution series in a 96-well plate using sterile water. We spotted 3-5 $\mu$ l onto specified plates using a 48-prong replica plating device and plates were incubated at specified temperatures for 3 days before being photographed.

\section{NAD ${ }^{+}$measurements}

$\mathrm{NAD}^{+}$measurements were made using a BioAssay Systems (Hayward, CA, USA) EnzyChrom $\mathrm{NAD}^{+} / \mathrm{NADH}$ Assay kit. Cultures $(2 \mathrm{ml})$ were grown overnight to saturation, diluted to $\mathrm{OD}_{600}=0.5$ in $5 \mathrm{ml}$ and allowed to double. $\mathrm{OD}_{600}$ measurements were taken before cultures were harvested and pellets resuspended in $125 \mu \mathrm{NAD}^{+}$extraction buffer. Ice-cold acidwashed glass beads (0.25 ml) were added. Lysis was achieved by applying samples to a Stretton Scientific (Stretton, Derbyshire, UK) Precellys 24 for $2 \times 10$ seconds at 6,500 rpm. Samples were recovered and assays were carried out according to the kit manufacturer's instructions. $\mathrm{NAD}^{+}$levels in each sample were quantified in duplicate. Correction factors based upon OD measurements were generated to account for increases in cell size after cell cycle arrest and applied to calculated $\mathrm{NAD}^{+}$concentrations.

Table 6

PCR primers for $\mathrm{W} 303$ deletion strains

\begin{tabular}{|c|c|c|}
\hline Primer & Alias & Sequence \\
\hline 1280 & BNA2 5' & CTCGACGCTGATTGGCTAA \\
\hline 1281 & BNA2 3' & $\begin{array}{l}\text { GTAACCAGTACGAAAAAAGATA } \\
\text { CATTT }\end{array}$ \\
\hline 1278 & NPTI 5' & $\begin{array}{l}\text { CATTGTGATTTTATTCAATGTTT } \\
\text { СTTT }\end{array}$ \\
\hline 1279 & NPTI 3' & C A G G G T T T G A A G A C A G G T \\
\hline
\end{tabular}




\section{Abbreviations}

DDR: DNA-damage response; ds: double stranded; DSB: double-strand break; ESR: environmental stress response; GO: Gene Ontology; QT: quality threshold; ss: singlestranded; STRE: stress-response element.

\section{Authors' contributions}

AG designed and carried out the majority of the experiments, analyzed the data and drafted and edited the manuscript. GL, DCS, and DJW processed and analyzed array data. KJ and AW carried out GOstats analysis. LW and HP carried out experiments. DL designed experiments and drafted and edited the manuscript.

\section{Additional data files}

The following additional data are available with the online version of this paper. Additional data file 1 is a figure showing RT-PCR analysis of heat shock gene expression. Additional data file 2 is a figure showing quality control of microarray strains and samples. Additional data file 3 includes tables listing differentially expressed genes in $c d c 13-1$ strains and genes in QT clusters 1-13. Additional data file 4 includes tables listing results from GOstats analyses. Additional data file 5 is a figure showing expression of $H S P 12, M S C 1$ and $C T T 1$ during the microarray time course. Additional data file 6 includes tables listing differentially expressed genes in both $c d c 13^{-1}$ and $t l c 1 \Delta$ and genes altered in $c d c 13-1$ but not in $t l c 1 \Delta$. Additional data file 7 includes tables listing transcription factor genes up-regulated and down-regulated in $c d c 13-1$ strains.

\section{Acknowledgements}

We would like to thank Jürg Bähler for critical reading of the manuscript and members of CISBAN for helpful discussions. We are grateful to Stephen Addinall for help with BioGrid and to Allyson Lister for assistance with the ArrayExpress submission. This work was supported by the BBSRC CISBAN grant (BB/C008200/I).

\section{References}

I. Lydall D: Hiding at the ends of yeast chromosomes: telomeres, nucleases and checkpoint pathways. J Cell Sci 2003, I | 6:4057-4065.

2. Longhese MP, Foiani M, Muzi-Falconi M, Lucchini G, Plevani P: DNA damage checkpoint in budding yeast. $E M B O J 1998$, I 7:5525-5528.

3. Longhese MP: DNA damage response at functional and dysfunctional telomeres. Genes Dev 2008, 22: I 25- | 40.

4. Cech TR: Beginning to understand the end of the chromosome. Cell 2004, I | 6:273-279.

5. Lundblad V, Blackburn $\mathrm{EH}$ : An alternative pathway for yeast telomere maintenance rescues estl-senescence. Cell 1993, 73:347-360.

6. Lundblad V, Szostak JW: A mutant with a defect in telomere elongation leads to senescence in yeast. Cell 1989, 57:633-643.

7. d'Adda di Fagagna F, Reaper PM, Clay-Farrace L, Fiegler H, Carr P, Von Zglinicki T, Saretzki G, Carter NP, Jackson SP: A DNA damage checkpoint response in telomere-initiated senescence. Nature 2003, 426:194-198.

8. Zubko MK, Lydall D: Linear chromosome maintenance in the absence of essential telomere-capping proteins. Nat Cell Biol
2006, 8:734-740.

9. Garvik B, Carson M, Hartwell L: Single-stranded DNA arising at telomeres in cdcl 3 mutants may constitute a specific signal for the RAD9 checkpoint. Mol Cell Biol 1995, I 5:6 I 28-6 I 38.

10. Grandin N, Damon C, Charbonneau M: CdcI 3 prevents telomere uncapping and Rad50-dependent homologous recombination. EMBO J 200I, 20:6I27-6I39.

II. Blasco MA: Telomeres and human disease: ageing, cancer and beyond. Nat Rev Genet 2005, 6:61 I-622.

12. Lin J, Zakian VA: The Saccharomyces CDCI 3 protein is a singlestrand TGI-3 telomeric DNA-binding protein in vitro that affects telomere behavior in vivo. Proc Natl Acad Sci USA 1996, 93: $13760-13765$

13. Nugent $\mathrm{Cl}$, Hughes TR, Lue NF, Lundblad V: Cdcl3p: a singlestrand telomeric DNA-binding protein with a dual role in yeast telomere maintenance. Science 1996, 274:249-252.

14. Evans SK, Lundblad V: Est I and CdcI3 as comediators of telomerase access. Science 1999, 286: II7-I 20.

15. Pennock E, Buckley K, Lundblad V: CdcI 3 delivers separate complexes to the telomere for end protection and replication. Cell 200I, I 04:387-396.

16. Bianchi A, Negrini S, Shore D: Delivery of yeast telomerase to a DNA break depends on the recruitment functions of $\mathrm{Cdcl} 3$ and Est I. Mol Cell 2004, 16:139-146.

17. Maringele L, Lydall D: EXOI-dependent single-stranded DNA at telomeres activates subsets of DNA damage and spindle checkpoint pathways in budding yeast yku70Delta mutants. Genes Dev 2002, 16:1919-1933.

18. Lydall D, Weinert T: Yeast checkpoint genes in DNA damage processing: implications for repair and arrest. Science 1995, 270:|488-|49|.

19. Qi H, Li TK, Kuo D, Nur EKA, Liu LF: Inactivation of Cdc I 3p triggers MECl-dependent apoptotic signals in yeast. J Biol Chem 2003, 278: $15136-15|4|$.

20. Wysocki R, Kron SJ: Yeast cell death during DNA damage arrest is independent of caspase or reactive oxygen species. J Cell Biol 2004, 166:3 I I-3 I6.

21. Weinert TA, Kiser GL, Hartwell LH: Mitotic checkpoint genes in budding yeast and the dependence of mitosis on DNA replication and repair. Genes Dev 1994, 8:652-665.

22. Nautiyal S, DeRisi JL, Blackburn EH: The genome-wide expression response to telomerase deletion in Saccharomyces cerevisiae. Proc Natl Acad Sci USA 2002, 99:9316-9321.

23. Zubko MK, Maringele L, Foster SS, Lydall D: Detecting repair intermediates in vivo: effects of DNA damage response genes on single-stranded DNA accumulation at uncapped telomeres in budding yeast. Methods Enzymol 2006, 409:285-300.

24. Gasch AP, Spellman PT, Kao CM, Carmel-Harel O, Eisen MB, Storz $G$, Botstein D, Brown PO: Genomic expression programs in the response of yeast cells to environmental changes. Mol Biol Cell 2000, I I:424 |-4257.

25. Smyth GK: Linear models and empirical bayes methods for assessing differential expression in microarray experiments. Stat Appl Genet Mol Biol 2004, 3:Article3.

26. Falcon S, Gentleman R: Using GOstats to test gene lists for GO term association. Bioinformatics 2007, 23:257-258.

27. Gasch AP, Huang M, Metzner S, Botstein D, Elledge SJ, Brown PO: Genomic expression responses to DNA-damaging agents and the regulatory role of the yeast ATR homolog Meclp. Mol Biol Cell 200I, I 2:2987-3003.

28. Lee SE, Pellecioli A, Demeter J, Vaze MP, Gasch AP, Malkova A, Brown PO, Botstein D, Stearns T, Foiani M, Haber JE: Genomic expression in yeast responding to $\mathrm{HO}$ endonuclease cleavage. In Biological Responses To DNA Damage Volume 65. Plainview, New York: Cold Spring Harbour Laboratory Press; 2000:303-3 I4.

29. Martinez-Pastor MT, Marchler G, Schuller C, Marchler-Bauer A, Ruis $H$, Estruch F: The Saccharomyces cerevisiae zinc finger proteins Msn2p and Msn4p are required for transcriptional induction through the stress response element (STRE). EMBO J 1996, I 5:2227-2235.

30. Orlando DA, Lin CY, Bernard A, Wang JY, Socolar JE, Iversen ES, Hartemink AJ, Haase SB: Global control of cell-cycle transcription by coupled CDK and network oscillators. Nature 2008 , 453:944-947.

31. Harbison CT, Gordon DB, Lee TI, Rinaldi NJ, Macisaac KD, Danford TW, Hannett NM, Tagne JB, Reynolds DB, Yoo J, Jennings EG, Zeitlinger J, Pokholok DK, Kellis M, Rolfe PA, Takusagawa KT, Lander ES, Gifford DK, Fraenkel E, Young RA: Transcriptional regulatory 
code of a eukaryotic genome. Nature 2004, 43 I:99- I 04.

32. Heyer LJ, Kruglyak S, Yooseph S: Exploring expression data: identification and analysis of coexpressed genes. Genome Res 1999, 9: I 106-III5.

33. Askree SH, Yehuda T, Smolikov S, Gurevich R, Hawk J, Coker C, Krauskopf A, Kupiec M, McEachern MJ: A genome-wide screen for Saccharomyces cerevisiae deletion mutants that affect telomere length. Proc Natl Acad Sci USA 2004, I 0 I:8658-8663.

34. Gatbonton T, Imbesi M, Nelson M, Akey JM, Ruderfer DM, Kruglyak L, Simon JA, Bedalov A: Telomere length as a quantitative trait: genome-wide survey and genetic mapping of telomere length-control genes in yeast. PLoS genetics 2006, 2:e35.

35. Addinall S, Downey M, Yu M, Zubko MK, Dewar J, Leake A, Hallinan J, Shaw O, James K, Wilkinson DJ, Wipat A, Durocher D, Lydall D: A genome-wide suppressor and enhancer analysis of cdcl3-I reveals varied cellular processes influencing telomere capping in Saccharomyces cerevisiae. Genetics 2008 in press.

36. Stark C, Breitkreutz B], Reguly T, Boucher L, Breitkreutz A, Tyers M: BioGRID: a general repository for interaction datasets. Nucleic Acids Res 2006, 34:D535-539.

37. Breitkreutz BJ, Stark C, Reguly T, Boucher L, Breitkreutz A, Livstone M, Oughtred R, Lackner DH, Bahler J, Wood V, Dolinski K, Tyers M: The BioGRID Interaction Database: 2008 update. Nucleic Acids Res 2008, 36:D637-640.

38. Breitkreutz BJ, Stark C, Tyers M: Osprey: a network visualization system. Genome Biol 2003, 4:R22.

39. Panozzo C, Nawara M, Suski C, Kucharczyka R, Skoneczny M, Becam AM, Rytka J, Herbert C): Aerobic and anaerobic NAD+ metabolism in Saccharomyces cerevisiae. FEBS Lett 2002, 5 I 7:97-102.

40. Sandmeier JJ, Celic I, Boeke JD, Smith JS: Telomeric and rDNA silencing in Saccharomyces cerevisiae are dependent on a nuclear NAD(+) salvage pathway. Genetics 2002, 160:877-889.

4I. Bieganowski P, Brenner C: Discoveries of nicotinamide riboside as a nutrient and conserved NRK genes establish a PreissHandler independent route to NAD+ in fungi and humans. Cell 2004, I I 7:495-502.

42. Saccharomyces Genome Database [http://db.yeastgenome.org/ cgi-bin/GO/goTerm.pl?goid=6769]

43. Anderson RM, Bitterman KJ, Wood JG, Medvedik O, Cohen H, Lin SS, Manchester JK, Gordon JI, Sinclair DA: Manipulation of a nuclear NAD+ salvage pathway delays aging without altering steady-state NAD+ levels. J Biol Chem 2002, 277:|888|-|8890.

44. Michan S, Sinclair D: Sirtuins in mammals: insights into their biological function. Biochem J 2007, 404: I- I3.

45. Michishita E, McCord RA, Berber E, Kioi M, Padilla-Nash H, Damian M, Cheung P, Kusumoto R, Kawahara TL, Barrett JC, Chang HY, Bohr VA, Ried T, Gozani O, Chua KF: SIRT6 is a histone H3 lysine 9 deacetylase that modulates telomeric chromatin. Nature 2008, 452:492-496.

46. Smith JS, Brachmann CB, Celic I, Kenna MA, Muhammad S, Starai VJ, Avalos JL, Escalante-Semerena JC, Grubmeyer C, Wolberger C, Boeke JD: A phylogenetically conserved NAD+-dependent protein deacetylase activity in the Sir2 protein family. Proc Natl Acad Sci USA 2000, 97:6658-6663.

47. Enomoto S, Glowczewski L, Lew-Smith J, Berman JG: Telomere cap components influence the rate of senescence in telomerasedeficient yeast cells. Mol Cell Biol 2004, 24:837-845.

48. Blackburn EH, Chan S, Chang J, Fulton TB, Krauskopf A, McEachern M, Prescott J, Roy J, Smith C, Wang H: Molecular manifestations and molecular determinants of telomere capping. Cold Spring Harbor Symp Quant Biol 2000, 65:253-263.

49. Mandell JG, Bahler J, Volpe TA, Martienssen RA, Cech TR: Global expression changes resulting from loss of telomeric DNA in fission yeast. Genome Biol 2005, 6:RI.

50. Passos JF, Saretzki G, Ahmed S, Nelson G, Richter T, Peters H, Wappler I, Birket MJ, Harold G, Schaeuble K, Birch-Machin MA, Kirkwood TB, von Zglinicki T: Mitochondrial dysfunction accounts for the stochastic heterogeneity in telomere-dependent senescence. PLOS Biol 2007, 5:el I0.

51. Watson A, Mata J, Bahler J, Carr A, Humphrey T: Global gene expression responses of fission yeast to ionizing radiation. Mol Biol Cell 2004, I 5:85 I-860.

52. Shelton DN, Chang E, Whittier PS, Choi D, Funk WD: Microarray analysis of replicative senescence. Curr Biol 1999, 9:939-945.

53. Adams A, Gottschling DE, Kaiser CA, Stearns T: Methods in Yeast Genetics New York: Cold Spring Harbour Laboratory Press; 1997.

54. Lyne R, Burns G, Mata J, Penkett CJ, Rustici G, Chen D, Langford C Vetrie $D$, Bahler J: Whole-genome microarrays of fission yeast: characteristics, accuracy, reproducibility, and processing of array data. BMC genomics 2003, 4:27.

55. Vandesompele J, De Preter K, Pattyn F, Poppe B, Van Roy N, De Paepe A, Speleman F: Accurate normalization of real-time quantitative RT-PCR data by geometric averaging of multiple internal control genes. Genome Biol 2002, 3:RESEARCH0034.

56. SyMBA [http://symba.sourceforge.net]

57. Bioconductor [http://www.bioconductor.org]

58. Tong $\mathrm{AH}$, Evangelista $\mathrm{M}$, Parsons $\mathrm{AB}, \mathrm{Xu} \mathrm{H}$, Bader $\mathrm{GD}$, Page N, Robinson M, Raghibizadeh S, Hogue CW, Bussey $H$, Andrews $B$, Tyers $M$, Boone C: Systematic genetic analysis with ordered arrays of yeast deletion mutants. Science 200I, 294:2364-2368.

59. Schiestl RH, Gietz RD: High efficiency transformation of intact yeast cells using single stranded nucleic acids as a carrier. Curr Genet 1989, 16:339-346.

60. Downey M, Houlsworth R, Maringele L, Rollie A, Brehme M, Galicia S, Guillard S, Partington M, Zubko MK, Krogan NJ, Emili A, Greenblatt JF, Harrington L, Lydall D, Durocher D: A genome-wide screen identifies the evolutionarily conserved KEOPS complex as a telomere regulator. Cell 2006, I 24: I I55- I 68.

6I. Zubko MK, Guillard S, Lydall D: Exol and Rad24 differetially regulate generation of ssDNA at telomeres of Saccharomyces cerevisiae cdc I3-I mutants. Genetics 2004, I 68: I03-I I5. 